\title{
Multiple Imputation of Missing Race and Ethnicity in CDC COVID- 19 Case-Level Surveillance Data
}

\author{
Guangyu Zhang ${ }^{1, *}$, Charles E. Rose ${ }^{1}$, Yujia Zhang ${ }^{1}$, Rui Li $^{2}$, Florence C. Lee ${ }^{1}$, \\ Greta Massetti ${ }^{1}$ and Laura E. Adams ${ }^{1}$
}

\author{
${ }^{1}$ CDC COVID-19 Response Team, Centers for Disease Control and Prevention, Atlanta, Georgia \\ ${ }^{2}$ Health Resources and Services Administration, Rockville, Maryland, USA
}

\begin{abstract}
The COVID-19 pandemic has resulted in a disproportionate burden on racial and ethnic minority groups, but incompleteness in surveillance data limits understanding of disparities. CDC's case-based surveillance system contains case-level information on most COVID-19 cases in the United States. Data analyzed in this paper contain COVID-19 cases with case-level information through September 25, 2020, which represent $70.9 \%$ of all COVID-19 cases reported to CDC during the period. Case-level surveillance data are used to investigate COVID-19 disparities by race/ethnicity, sex, and age. However, demographic information on race and ethnicity is missing for a substantial percentage of COVID-19 cases (e.g., $35.8 \%$ and $47.2 \%$ of cases analyzed were missing race and ethnicity information, respectively). Our goal in this study was to impute missing race and ethnicity to derive more accurate incidence and incidence rate ratio (IRR) estimates for different racial and ethnic groups, and evaluate the results from imputation compared to complete case analysis, which involves removing cases with missing race/ethnicity information from the analysis. Two multiple imputation (MI) models were developed. Model 1 imputes race using six binary race variables, and Model 2 imputes race as a composite multinomial variable. Our evaluation found that compared with complete case analysis, MI reduced biases and improved coverage on incidence and IRR estimates for all race/ethnicity groups, except for the NonHispanic Multiple/other group. Our research highlights the importance of supplementing complete case analysis with additional methods of analysis to better describe racial and ethnic disparities. When race and ethnicity data are missing, multiple imputation may provide more accurate incidence and IRR estimates to monitor these disparities in tandem with efforts to improve the collection of race and ethnicity information for pandemic surveillance.
\end{abstract}

Keywords: Multiple Imputation, Missing Data, Race and Ethnicity, Health Equity.

\section{INTRODUCTION}

The COVID-19 pandemic has disproportionately affected several racial and ethnic groups, with disparities reported in the number of cases, hospitalizations, and deaths [1-4]. However, race and ethnicity are infrequently reported, creating challenges in data analysis and interpretation [5]. Missing data on race and ethnicity are a common challenge in health and health care data systems, despite efforts to improve the accuracy of data collected [6-8]. Missing data for race and ethnicity is a key barrier in monitoring and addressing health disparities among racial and ethnic groups. The CDC case-based surveillance system includes data reported by state and local health departments including case-level information on most COVID-19 cases in the United States (https://www.cdc. gov/coronavirus/2019-ncov/downloads/pui-form.pdf).

Information on race and ethnicity is missing for a large proportion of COVID-19 cases reported to the CDC, with $35 \%$ missing as of January 13, 2022 (https://covid.cdc.gov/covid-data-tracker/\#

demographics, last accessed January 14, 2022). Incomplete data on race and ethnicity limits

*Address correspondence to this author at the CDC COVID-19 Response Team, Centers for Disease Control and Prevention, Atlanta, GA, Georgia; E-mail:VHA1@CDC.GOV thorough and accurate investigation of racial and ethnic disparities in COVID-19 incidence.

Though a common practice, complete case analysis (removing subjects with missing race/ethnicity information from calculations) may yield biased results [9]. Recent studies have explored alternative methods to complete case analysis to address missingness in race and ethnicity. For example, Fiscella et al., [10] and Elliott et al., [11-12] developed Bayesian Surname and Geocoding and Bayesian Improved Surname and Geocoding (BISG) methods to estimate the posterior probability of an individual belonging to a given racial/ethnic group using U.S. Census geospatial and U.S. Census surname data. Grundmeier et al., [13] developed a Multiple Imputation (MI) model which included the posterior probability of racial/ethnic membership derived from the BISG method as well as demographic and clinical characteristics related to an individual's race/ethnicity. Ma et al., [14] explored MI methods to impute missing race and ethnicity with ZIP code-level information (e.g., racial distribution and income) and individual-level information (e.g., age and mortality) as covariates. Kim et al., [15] imputed missing race and ethnicity information using deep learning methods with around 15,000 features including demographic information and clinical events. Labgold et al., [16] applied quantitative bias analysis (i.e., BISG 
based imputation followed by probabilistic bias analysis) to account for missing race and ethnicity.

Using the $\mathrm{Ml}$ method to impute missing race and ethnicity information has several advantages. First, it can include variables related to race and ethnicity, as well as variables related to missingness on race and ethnicity. Second, MI creates several imputed data sets; the variability within and between the imputed datasets reflects the uncertainty about the missing data. Third, Ml techniques have been widely used for several decades and can be performed using standard statistical software, e.g., SAS, R, MICE, STATA. Sequential regression multivariate imputation (SRMI) is a commonly used strategy to construct an imputation model [9, 17-23]. It constructs an imputation model for each variable with missing data. It is flexible and can include variables of different distributions. Imputation methods described in this paper follow the SRMI approach.

Our purpose was to develop MI models to impute missing race and ethnicity information in the CDC COVID-19 case-level surveillance data and evaluate the performance of these models regarding the incidence and incidence rate ratio estimates of COVID19 cases by race/ethnicity. Two MI models were constructed-one where race is imputed using six binary variables and one where race is imputed as a composite multinomial variable-and applied to the case-level surveillance data. Then, an evaluation study assessed the performance of these models.

\section{MULTIPLE IMPUTATION OF MISSING RACE AND ETHNICITY IN CDC COVID-19 CASE-LEVEL SURVEILLANCE DATA}

\subsection{Missing Data on Race and Ethnicity in CDC COVID-19 Case-Level Surveillance Data}

Our analysis used case-level surveillance data reported from January 20, 2020, through September 25,2020 . Race was reported as one or more of the following race groups: Black, White, Asian, American Indian/Alaska Native (AIAN), Native Hawaiian/Other Pacific Islander (NHPI), and Other race. Records with two or more race groups selected were categorized as multiple race; records with no race categories selected were categorized as missing race. Ethnicity was reported as either Hispanic/Latino or NonHispanic/Latino; records with no ethnicity categories selected were categorized as missing ethnicity. Table S1 in the supplemental materials describes the number of COVID-19 cases reported and the percentage of cases with missing race and ethnicity information for each of the 50 states and the District of Columbia (DC). Missingness of race and ethnicity varied by state, with missingness of race ranging from $0.49 \%$ (DC) to $99.99 \%(\mathrm{OK})$, and missingness of ethnicity ranging from $10.11 \% \quad(W V)$ to $99.99 \%$ (OK). Overall, missingness of race was $35.82 \%$, and missingness of ethnicity was $47.24 \%$. Race and ethnicity were imputed as two separate variables, i.e., not combined into one variable because missing data patterns differed by race and ethnicity.

\subsection{Multiple Imputation Models}

Our imputation models assumed race and ethnicity data were missing at random (MAR) (i.e., the probability of missingness was not related to the missing data but was related to some of the observed data). To increase the plausibility of the MAR assumption, Little and Rubin [9] recommend including numerous covariates related to the missingness and/or the response variable(s) in the imputation model. Variables related to race and ethnicity as well as variables related to the missingness of race and ethnicity information were identified and included in the imputation model. Case-level surveillance data contains demographic, exposure, and clinical information on each case including age, sex, medical conditions and risk behaviors, clinical course, and symptoms, which could be closely associated with the probability of being a COVID-19 case by different race or ethnicity groups. However, most of this information is missing for more than $80 \%$ of the cases, which limits their usability in the MI model. Thus, we included only the case's age $(0.2 \%$ missing $)$ and sex $(2.0 \%$ missing $)$ variables in the MI. Case-level surveillance data also contain information on an individual's county of residence, state of residence, and Federal Information Processing Standards (FIPS) information. It would be desirable to include data at a finer resolution, e.g., zip code, in the prediction of missing race/ethnicity. However, using a finer resolution such as census block or zip code was not feasible given the lack of finer resolution information in the case-level surveillance data. The five-digit FIPS code can be used to link the case-level data to county-level datasets to predict the probability of individual-level characteristics of the residents in the geographic areas. To improve the MI model, three county-level datasets were linked to the case-level surveillance data using FIPS code: County Health Rankings (2018), Vintage county population data (2018), and CDC/ATSDR Social Vulnerability Index (SVI) data (2018), the latest data available at the 


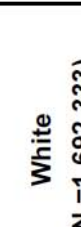

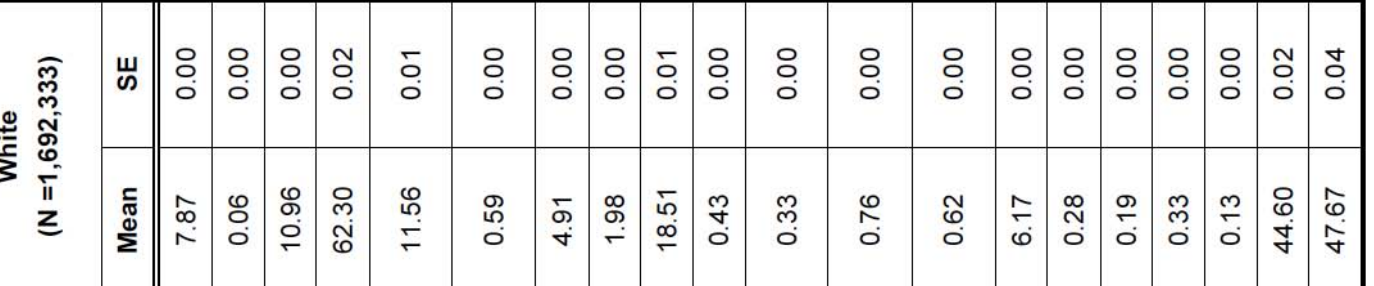

咅离

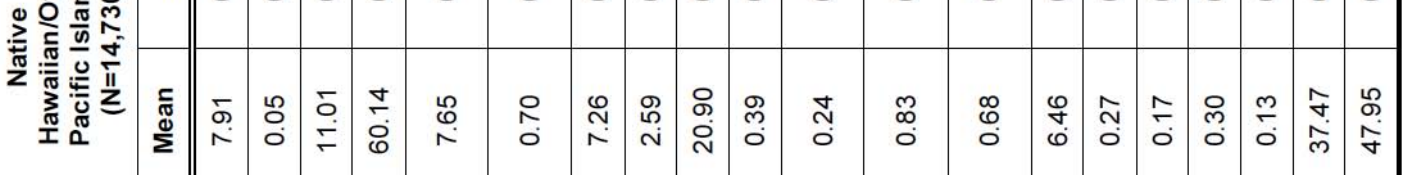
童哭 을

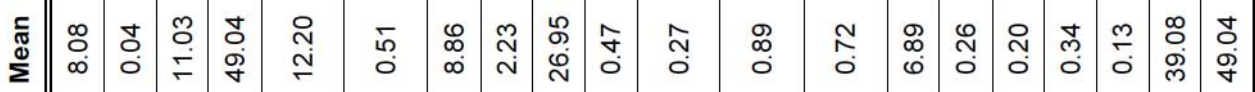

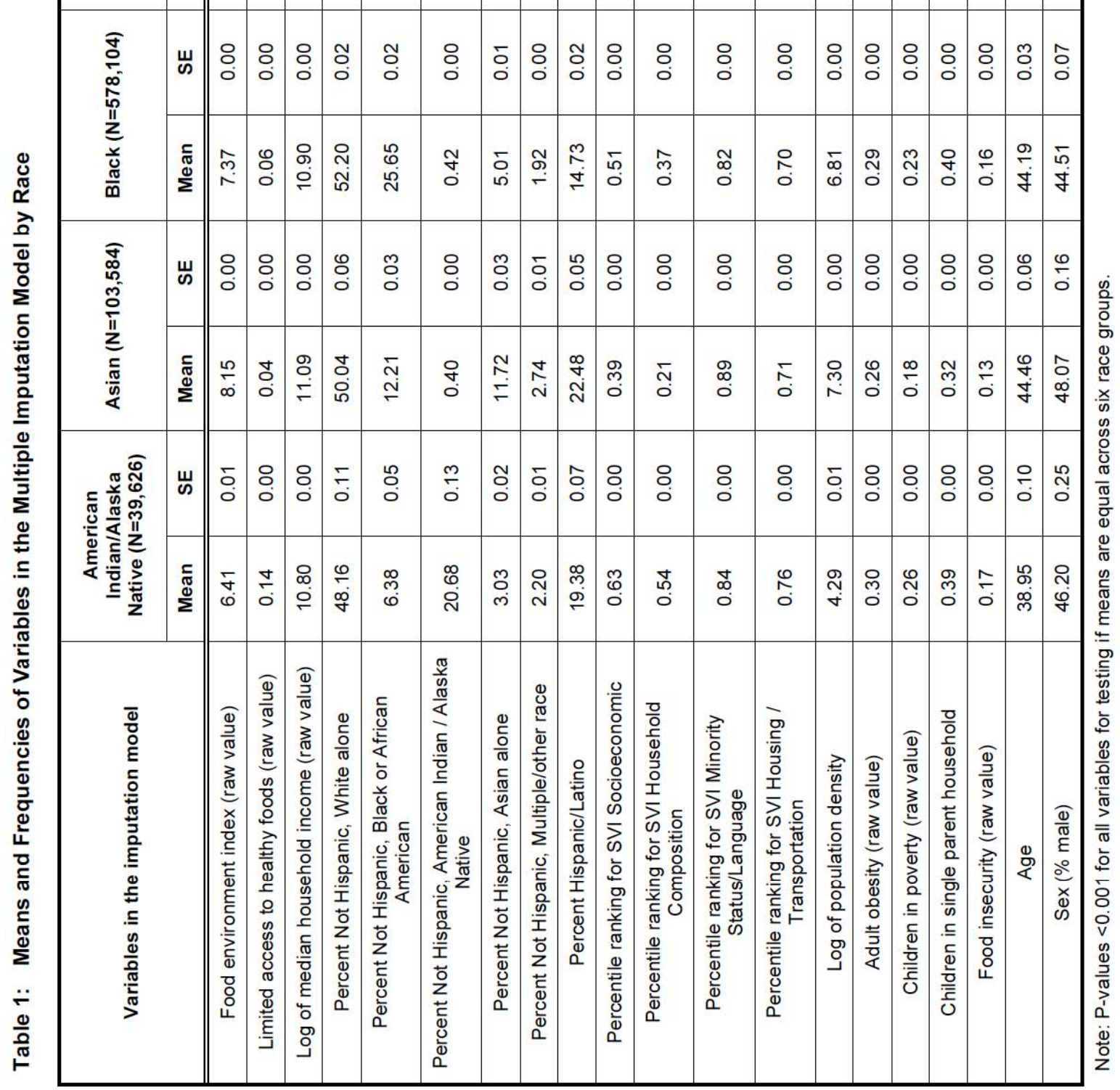


time of our study. These county-level datasets included demographics, census information, and CDC SVI. We conducted exploratory data analysis using linear and logistic regression models to evaluate the associations between these county-level variables and race and ethnicity, as well as the missingness of race and ethnicity. We selected 18 county-level variables for inclusion in the imputation model. Table 1 contains the means and percentages of variables selected for the imputation model by race. Tables $\mathbf{S} 2$ and $\mathbf{S 2 - A}$ in the supplemental materials contain means and percentages of these variables by ethnicity, and by missingness on race and ethnicity.

Two MI models to impute race were constructed. Model 1 used six binary (Yes/No) race variables and imputed each race variable (Black, White, Asian, American Indian/Alaska Native, Native Hawaiian/Other Pacific Islander, Other) separately. After imputation, an individual's race was categorized based on the imputed values of these six variables. If only one of the six variables was imputed as "Yes" then the individual's race was defined by the variable with "Yes". If more than two race variables were imputed as "Yes" then the person was defined as Multiple race. Multiple race and other race were combined into Multiple/other race category for analysis. Model 2 treated race as a multinomial variable with six categories (Black, White, Asian, American Indian/Alaska Native, Native Hawaiian/Other Pacific Islander, Multiple/other) and imputed the missing values as one of the six categories directly from the model.

For both models, ethnicity was imputed as a binary variable with two levels (Hispanic/Latino and NonHispanic/Latino). The MI models were implemented using SAS Proc $\mathrm{Ml}$ with the fully conditional specification procedure [24]. The discriminate function was used for categorical variables and a regression model for continuous variables. Ten imputations were conducted for each imputation model. After MI, race, and ethnicity were combined into a single analysis variable as Hispanic/Latino, Non-Hispanic White (NH White), Non-Hispanic Black (NH Black), Non-Hispanic Asian (NH Asian), Non-Hispanic American Indian/Alaska Native (NH AIAN), Non-Hispanic Native Hawaiian/Other Pacific Islander (NH NHPI), and NonHispanic Multiple/other (NH Multiple/other).

Statistical analysis was conducted separately for each imputed dataset. Incidence (per 1,000) and incidence rate ratio (IRR; $\mathrm{NH}$ White as the reference group) were estimated by race/ethnicity over the 50 states and DC for each imputed dataset. State to state variability was accounted for by treating the state and $\mathrm{DC}$ as a cluster in a Poisson model (using GEE to account for the clustering) and implemented using SAS Proc GENMOD procedure with the population size as the offset. Results were combined using Rubin's MI combining rules for the 10 imputation datasets using the SAS MIANALYZE procedure [25-29]. These results were compared with those from the complete case analysis.

\subsection{Results from Multiple Imputation Models and Complete Case Analysis}

Incidence per 1,000 population and incidence rate ratios by race/ethnicity were assessed from the complete case analysis and two MI models (Table 2). Case-level surveillance data contained $49.39 \%$ missingness on race/ethnicity $(35.82 \%$ and $47.24 \%$ missingness on race and ethnicity, respectively); as a result, the incidence estimates based on complete case analysis yielded incidence estimates by race/ethnicity approximately $50 \%$ lower than those based on the MI data. Based on the complete case analysis, all race/ethnicity groups except $\mathrm{NH}$ Asian had a higher risk of COVID-19 compared to NH White, with IRR estimates ranging from 2.13 (95\% confidence interval $(\mathrm{Cl})=1.88,2.42)(\mathrm{NH}$ Black $)$ to $3.06(95 \% \mathrm{Cl}=2.30$, 4.07) (NH Multiple/other). The two imputation models yielded incidence and IRR estimates similar to each other, where all groups except $\mathrm{NH}$ Asian had higher IRR compared to $\mathrm{NH}$ White, with IRR ranging from 1.84 $(95 \% \mathrm{Cl}=1.53,2.22)$ among $\mathrm{NH}$ Black to $4.47(95 \% \mathrm{Cl}$ $=2.26,8.87$ ) among $\mathrm{NH}$ Multiple/other based on Model 1 , and from $1.94(95 \% \mathrm{Cl}=1.61,2.33)$ among $\mathrm{NH}$ Black to $5.13(95 \% \mathrm{Cl}=2.35,11.22)$ among $\mathrm{NH}$ Multiple/other based on Model 2. The IRR estimates based on the imputation models were higher than the complete case IRR results in two groups, $\mathrm{NH}$ Multiple/other and NH NHPI; however, the statistical significance levels of complete case analysis remain unchanged after $\mathrm{Ml}$ (e.g., among NH NHPI, IRR $=2.99$, $95 \% \mathrm{Cl}=1.65,5.41$ from complete case analysis; IRR $=4.18,95 \% \mathrm{Cl}=2.28,7.66$ from Model $1 ; \mathrm{IRR}=3.95$, $95 \% \mathrm{Cl}=2.11,7.39$ from Model 2).

\section{EVALUATION OF MI MODELS}

An evaluation was conducted to assess the performance of the two Ml models. Case-level surveillance data from Minnesota (MN) and Utah (UT) were used because the percent missing race and ethnicity were low (MN: race $(11.9 \%)$ and ethnicity 
Table 2: Incidence per 1,000 and Incidence Rate Ratio (IRR) Estimates Based on Complete Case Analysis and Multiple Imputation from Case-Level Data Across 50 States and DC

\begin{tabular}{|c|c|c|c|c|c|c|}
\hline \multirow[b]{2}{*}{ Race/ethnicity } & \multicolumn{2}{|c|}{ Complete case analysis } & \multicolumn{2}{|c|}{$\begin{array}{l}\text { Multiple imputation model } 1 \\
\text { ( } 6 \text { individual race variables) }\end{array}$} & \multicolumn{2}{|c|}{$\begin{array}{l}\text { Multiple imputation model } 2 \\
\text { (1 multinomial race variable) }\end{array}$} \\
\hline & $\begin{array}{l}\text { Incidence } \\
(95 \% \mathrm{Cl})\end{array}$ & $\begin{array}{c}\text { IRR } \\
(95 \% \mathrm{CI})\end{array}$ & $\begin{array}{l}\text { Incidence } \\
(95 \% \mathrm{Cl})\end{array}$ & $\begin{array}{c}\text { IRR } \\
(95 \% \mathrm{CI})\end{array}$ & $\begin{array}{l}\text { Incidence } \\
(95 \% \mathrm{Cl})\end{array}$ & $\begin{array}{c}\text { IRR } \\
(95 \% \mathrm{Cl})\end{array}$ \\
\hline Hispanic/Latino & $\begin{array}{c}12.10 \\
(6.31,23.20)\end{array}$ & $\begin{array}{c}2.34 \\
(1.32,4.13)\end{array}$ & $\begin{array}{c}23.30 \\
(14.56,37.29)\end{array}$ & $\begin{array}{c}2.06 \\
(1.25,3.41)\end{array}$ & $\begin{array}{c}23.30 \\
(14.45,37.57)\end{array}$ & $\begin{array}{c}2.13 \\
(1.28,3.52)\end{array}$ \\
\hline NH White & $\begin{array}{c}5.18 \\
(4.26,6.30)\end{array}$ & Reference & $\begin{array}{c}11.28 \\
(8.84,14.41)\end{array}$ & Reference & $\begin{array}{c}10.96 \\
(8.63,13.92)\end{array}$ & Reference \\
\hline $\mathrm{NH}$ Asian & $\begin{array}{c}4.45 \\
(3.54,5.59)\end{array}$ & $\begin{array}{c}0.86 \\
(0.72,1.02)\end{array}$ & $\begin{array}{c}9.34 \\
(7.28,11.99)\end{array}$ & $\begin{array}{c}0.83 \\
(0.66,1.04)\end{array}$ & $\begin{array}{c}8.93 \\
(6.47,12.31)\end{array}$ & $\begin{array}{c}0.81 \\
(0.60,1.10)\end{array}$ \\
\hline NH Black & $\begin{array}{c}11.05 \\
(8.74,13.95)\end{array}$ & $\begin{array}{c}2.13 \\
(1.88,2.42)\end{array}$ & $\begin{array}{c}20.78 \\
(16.72,25.82)\end{array}$ & $\begin{array}{c}1.84 \\
(1.53,2.22)\end{array}$ & $\begin{array}{c}21.23 \\
(16.82,26.79)\end{array}$ & $\begin{array}{c}1.94 \\
(1.61,2.33)\end{array}$ \\
\hline NH Multiple/other & $\begin{array}{c}15.86 \\
(11.49,21.87)\end{array}$ & $\begin{array}{c}3.06 \\
(2.30,4.07)\end{array}$ & $\begin{array}{c}50.47 \\
(21.71,117.35)\end{array}$ & $\begin{array}{c}4.47 \\
(2.26,8.87)\end{array}$ & $\begin{array}{c}56.26 \\
(22.50,140.67)\end{array}$ & $\begin{array}{c}5.13 \\
(2.35,11.22)\end{array}$ \\
\hline $\mathrm{NH} \mathrm{NHPI}$ & $\begin{array}{c}15.50 \\
(8.42,28.52)\end{array}$ & $\begin{array}{c}2.99 \\
(1.65,5.41)\end{array}$ & $\begin{array}{c}47.19 \\
(26.59,83.76)\end{array}$ & $\begin{array}{c}4.18 \\
(2.28,7.66)\end{array}$ & $\begin{array}{c}43.27 \\
(23.66,79.13)\end{array}$ & $\begin{array}{c}3.95 \\
(2.11,7.39)\end{array}$ \\
\hline $\mathrm{NH}$ AIAN & $\begin{array}{c}11.33 \\
(6.02,21.35)\end{array}$ & $\begin{array}{c}2.19 \\
(1.19,4.02)\end{array}$ & $\begin{array}{c}27.27 \\
(15.86,46.90)\end{array}$ & $\begin{array}{c}2.42 \\
(1.34,4.37)\end{array}$ & $\begin{array}{c}29.65 \\
(16.10,54.63)\end{array}$ & $\begin{array}{c}2.70 \\
(1.40,5.22)\end{array}$ \\
\hline
\end{tabular}

NH: Non-Hispanic/Latino; NHPI: Native Hawaiian/Other Pacific Islander; AIAN: American Indian/Alaska Native.

$(16.7 \%)$; UT: race $(9.8 \%)$ and ethnicity $(10.9 \%))$; and the case-level data from MN and UT had different race and ethnicity compositions (e.g., MN case data had lower percentages of individuals in the American Indian/Alaska Native (0.83\%), Native Hawaiian/Other Pacific Islander $(0.22 \%)$ and Hispanic/Latino $(24.5 \%)$ groups, while UT case data had more than $2 \%$ of individuals in each race category and $46.1 \%$ of individuals in the Hispanic/Latino group). A total of 138,965 cases reported from MN and UT were assessed; 114,793 (83\%) had complete age, sex, race, and ethnicity and were used to estimate the "true" incidence and IRR for comparison when conducting the $\mathrm{Ml}$ and complete case analyses.

Using the target population (MN/UT, N=114,793), two levels of missingness for race and ethnicity (low (i.e., less than $20 \%$ missingness) and high (i.e., more than $40 \%$ missingness)) were generated as evaluation datasets, assuming MAR missingness. For the low percent of missingness (Evaluation 1), separate logistic regression models were first fitted for missing race and ethnicity using data from lowa (IA). IA was selected to derive parameters of MAR propensity models since it has low percentages of missingness on race (14.6\%) and ethnicity $(13.9 \%)$. The response variable was whether a subject had missing race and missing ethnicity. Age, sex, and 18 county-level variables (Table 1) were included as predictors, but only variables with $p$-values $\leq 0.05$ were retained in the final models. These parameter estimates were then used to calculate the probabilities of missing race and missing ethnicity for each person in the MN/UT population. Probabilities were compared with two randomly generated numbers from a Uniform $(0,1)$ distribution to decide if an individual has missing race and/or ethnicity. More details of the evaluation study can be found in Part 1 of the supplemental materials. Applying IA propensity models to the MN/UT population, $15 \%$ of subjects had missing data on race, $17.3 \%$ subjects had missing data on ethnicity, $26 \%$ subjects had missing values on combined race/ethnicity, on average. This procedure was then repeated using data from Pennsylvania (PA) to fit the propensity models (high percent of missingness; denoted as Evaluation 2). Applying propensity models from PA to the MN/UT population, approximately $44.1 \%$ of subjects had a missing race, $53.6 \%$ subjects had missing ethnicity, and $64.1 \%$ subjects had missing race and ethnicity.

This evaluation used the two aforementioned MI models to impute missing values on race and ethnicity with data from MN/UT. For each evaluation study, the procedure was repeated 100 times (i.e., each time two random numbers were generated for an individual to determine if the individual would have missing values on race and/or ethnicity) to create 100 replicates, and for each replicate 10 imputations were conducted. 
Incidence per 1,000 by race/ethnicity and IRR by race/ethnicity (with $\mathrm{NH}$ White as the reference group) were calculated using a Poisson model with GEE as the method to account for clustering within a county and the log of the county population as the offset. The parameter estimates for the MN/UT target population (i.e., before generating missing values) served as the reference standard. For comparison, incidence and IRR were estimated using the complete case analysis (MN/UT data after generating and removing missing values from the analysis). For Ml data, the Poisson model was fit to each imputed data, and the final estimates using the 10 multiply imputed datasets were derived using Rubin's combination rule. Bias (the difference between the target "true" value derived from the target population and the estimated value using $\mathrm{MI}$ or the complete case analyses), relative bias (100*bias/true value), mean width of $95 \% \mathrm{Cl}$ (i.e., the difference of the upper bound and the lower bound of $95 \% \mathrm{Cl}$ ) over 100 replicates and coverage rate were then calculated. Coverage was defined as one if the $95 \% \mathrm{Cl}$ covered the true value and zero otherwise.

Results of Evaluation 1 are shown in Table 3. The incidence estimates ranged from 7.17 ( $\mathrm{NH}$ White) to $64.90(\mathrm{NH} \mathrm{NHPI})$ per 1,000 for the target population. The complete case analysis yielded results with large biases across all race/ethnicity groups. Biases ranged from -21.55 (NH NHPI) to -2.08 (NH White) per 1,000; relative biases ranged from $-52.70 \%$ (NH AIAN) to $22.49 \%$ (Hispanic/Latino). Coverage rates were zero for all race/ethnicity groups. Using individual race variables (Model 1), Ml yielded incidence estimates close to the target population, with biases ranging from $-0.60(\mathrm{NH} \mathrm{NHPI})$ to 1.32 ( $\mathrm{NH}$ Multiple/other) per 1,000, and relative biases ranging from $-3.96 \%$ (NH AIAN) to $10.5 \%$ ( $\mathrm{NH}$ Multiple/other). Coverage rates were one for all race/ethnicity groups, which meant the $95 \% \mathrm{Cls}$ of all the 100 replicates covered the targeted estimates. Using the combined race variable (Model 2), MI yielded incidence estimates with slightly larger biases versus Model 1, with biases ranging from -2.51 ( $\mathrm{NH}$ Multiple/other) to 2.00 (NH NHPI) per 1,000, and relative bias ranging from $-19.97 \%$ ( $\mathrm{NH}$ Multiple/other) to $7.54 \%$ (NH Asian). Coverage rates were one for all race/ethnicity groups except the $\mathrm{NH}$ Multiple/other group, which had a coverage of 0.18 .

The true IRRs ranged from 1.72 (NH Asian) to 9.05 (NH NHPI) for the target population. Though there were large biases in terms of the incidence estimates, the IRR estimates based on complete case analysis were closer to the target population, with biases ranging from
-0.61 (NH AIAN) to 0.44 (Hispanic/Latino), and relative biases ranging from $-33.33 \%$ ( $\mathrm{NH}$ AIAN) to $9.09 \%$ (Hispanic/Latino), and only one group, NH AIAN, with a coverage rate of zero. The IRR estimates for the MI data in Model 1 were close to the target population with biases ranging from $-0.08(\mathrm{NH} N \mathrm{NHP})$ to $0.18(\mathrm{NH}$ Multiple/other) and relative biases ranging from $-3.83 \%$ ( $\mathrm{NH}$ AIAN) to $10.29 \%$ (NH Multiple/other). Coverage rates equaled to one for all race/ethnicity groups for Model 1. The IRR estimates using imputation Model 2 were similar to Model 1 , with biases ranging from -0.37 ( $\mathrm{NH}$ Multiple/other) to $0.18(\mathrm{NH} \mathrm{NHPI)}$ and relative biases ranging from $-21.14 \%$ ( $\mathrm{NH}$ Multiple/other) to $6.40 \%$ (NH Asian). For Model 2, coverage rates equaled to one for all race/ethnicity groups except $\mathrm{NH}$ Multiple/other group, which had a coverage of zero.

Table 4 shows the results of Evaluation 2, where the missing percentages on race and ethnicity were higher than those of Evaluation 1. The complete case analysis yielded larger biases in incidence estimates compared to Evaluation 1 because more subjects were removed from the analysis, with biases ranging from 27.53 (NH NHPI) to -4.85 ( $\mathrm{NH}$ AIAN) per 1,000 , relative biases ranging from $-85.52 \%$ (NH Black) to $-36.94 \%$ (NH AIAN), and two groups (Hispanic/Latino and $\mathrm{NH}$ AIAN) with coverage rates equal to one and remaining groups with coverage rates equal to zero. Multiple imputation Model 1 reduced biases for all groups except the $\mathrm{NH}$ Multiple/other group. Excluding $\mathrm{NH}$ Multiple/other group, biases using Model 1 ranged from -3.41 (NH NHPI) to 3.80 ( $\mathrm{NH}$ Asian) per 1,000, relative biases ranged from $-22.09 \%$ (NH AIAN) to $30.82 \%(\mathrm{NH}$ Asian), and coverage rates were $\geq 0.95$. The $\mathrm{NH}$ Multiple/other group had a bias of 9.58 per 1,000. Multiple imputation Model 2 imputed the combined race variable, the bias for $\mathrm{NH}$ Multiple/other group (-3.28 per $1,000)$ was smaller compared to that of imputation Model 1. However, it yielded a lower coverage for the $\mathrm{NH}$ Multiple/other race group due to the narrow $\mathrm{Cl}$. The narrow width of $\mathrm{Cl}$ suggests the incidence estimates across county are similar based on imputation Model 2, which leads to a small variance and a lower coverage rate. For the remaining groups, the results of Model 2 were close to Model 1.

The complete case analysis of Evaluation 2 yielded larger biases on IRR estimates compared to Evaluation 1 , with biases ranging from -2.27 ( $\mathrm{NH}$ Black) to 7.58 (NH NHPI) and relative biases ranging from $-53.79 \%$ (NH Black) to $101.64 \%$ (NH AIAN). The MI Models 1 and 2 reduced biases and improved coverage for all groups except $\mathrm{NH}$ Multiple/other group. 


\begin{tabular}{|c|c|c|c|c|c|c|c|c|c|c|c|c|c|c|c|c|}
\hline \multirow{5}{*}{ 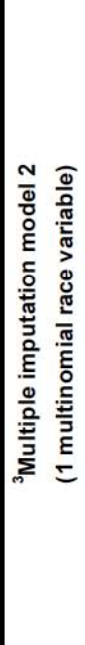 } & 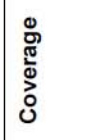 & $\stackrel{\leftrightarrow}{\circ}$ & $\stackrel{\circ}{\circ}$ & $\stackrel{\text { ¿ }}{-}$ & $\stackrel{\circ}{\circ}$ & $\stackrel{\infty}{\circ}$ & $\stackrel{\circ}{\circ}$ & $\stackrel{\circ}{\circ}$ & \multirow{5}{*}{ 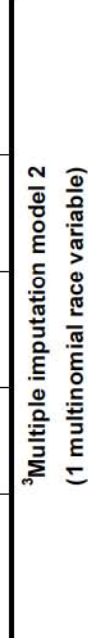 } & 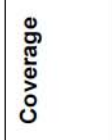 & $\stackrel{\circ}{\circ}$ & 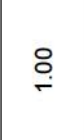 & $\stackrel{\circ}{\circ}$ & : & $\stackrel{\text { }}{\circ}$ & $\stackrel{\circ}{\circ}$ \\
\hline & 紊。 & $\begin{array}{l}\mathbb{N} \\
\mathscr{N}\end{array}$ & స్లి & $\begin{array}{l}\bar{D} \\
\stackrel{n}{n}\end{array}$ & $\begin{array}{l}\stackrel{0}{\not} \\
\infty \\
\infty\end{array}$ & 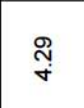 & 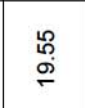 & $\underset{\infty}{\stackrel{\infty}{\infty}}$ & & 咅叮 & $\stackrel{\text { m}}{\longrightarrow}$ & $\stackrel{\mathscr{\leftrightarrow}}{\stackrel{\circ}{\circ}}$ & ָ̊ & $\stackrel{\infty}{\stackrel{\infty}{0}}$ & g & $\stackrel{\Re}{\stackrel{N}{\longrightarrow}}$ \\
\hline & 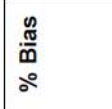 & $\stackrel{8}{\circ}$ & $\begin{array}{l}\infty \\
\stackrel{\infty}{\circ} \\
0\end{array}$ & 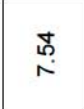 & $\stackrel{8}{\circ}$ & $\begin{array}{l}\hat{\circ} \\
\text { के }\end{array}$ & $\begin{array}{l}\infty \\
\stackrel{\infty}{\infty}\end{array}$ & $\begin{array}{l}\hat{y} \\
\dot{\varphi}\end{array}$ & & 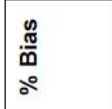 & 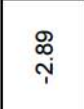 & $\begin{array}{l}q \\
G\end{array}$ & : & $\stackrel{\vec{T}}{\stackrel{\nabla}{\tau}}$ & $\stackrel{\text { ㅇ }}{\leftarrow}$ & $\stackrel{\stackrel{\leftrightarrow}{\circ}}{\uparrow}$ \\
\hline & 惫 & $\stackrel{\circ}{\circ}$ & ò. & ֶֻ. & $\stackrel{\widetilde{్}}{\circ}$ & ָூָ & 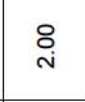 & \begin{tabular}{l}
$\infty$ \\
$\substack{\infty \\
\hdashline}$
\end{tabular} & & 兽 & $\frac{ \pm}{i}$ & $\overline{0}$ & $\stackrel{0}{0}$ & ồ & $\stackrel{\infty}{\circ}$ & ب̦ \\
\hline & 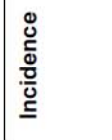 & 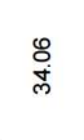 & $\underset{\sim}{\stackrel{d}{r}}$ & 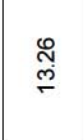 & $\begin{array}{l}\stackrel{\leftrightarrow}{0} \\
\stackrel{p}{0}\end{array}$ & $\begin{array}{l}\stackrel{\leftrightarrow}{0} \\
\stackrel{\circ}{0}\end{array}$ & $\begin{array}{l}8 \\
0 \\
0\end{array}$ & $\stackrel{\text { ్ }}{\sim}$ & & $\underset{\underline{\underline{\alpha}}}{\underline{\underline{\alpha}}}$ & $\stackrel{R}{r}$ & $\stackrel{\infty}{\sim}$ & $\underset{\sim}{\mathbb{*}}$ & $\stackrel{\text { m}}{\sim}$ & 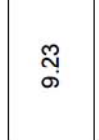 & $\stackrel{\leftrightarrow}{\leftrightarrow}$ \\
\hline \multirow{5}{*}{ 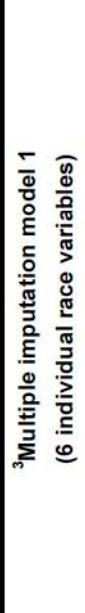 } & 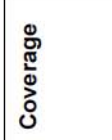 & $\stackrel{\leftrightarrow}{\circ}$ & $\stackrel{\leftrightarrow}{\circ}$ & $\stackrel{\text { \&̊ }}{\circ}$ & $\stackrel{\leftrightarrow}{\circ}$ & $\stackrel{\leftrightarrow}{\circ}$ & $\underset{\sim}{\stackrel{\circ}{+}}$ & $\stackrel{\leftrightarrow}{\circ}$ & \multirow{5}{*}{ 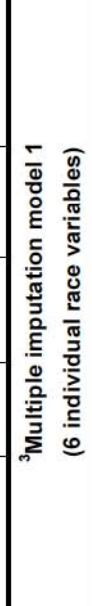 } & 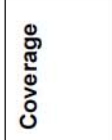 & $\stackrel{8}{\circ}$ & $\stackrel{8}{\circ}$ & 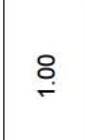 & 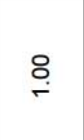 & $\stackrel{8}{\circ}$ & $\stackrel{\text { \&̊ }}{-}$ \\
\hline & 产可 & $\stackrel{\text { N }}{\stackrel{5}{\leftarrow}}$ & $\underset{\text { d }}{\stackrel{\nabla}{j}}$ & $\stackrel{\text { S }}{=}$ & $\begin{array}{l}\stackrel{0}{\Gamma} \\
\stackrel{\Gamma}{r}\end{array}$ & 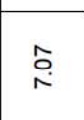 & $\stackrel{\mathscr{L}}{\underset{N}{N}}$ & $\stackrel{\infty}{\infty}$ & & 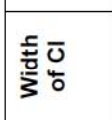 & 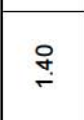 & $\stackrel{\stackrel{m}{\leftarrow}}{\leftarrow}$ & $\stackrel{\mathscr{\infty}}{\stackrel{\infty}{\infty}}$ & $\hat{\hat{O}}$ & $\frac{\mathscr{\rho}}{\dot{m}}$ & 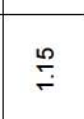 \\
\hline & $\therefore \frac{\pi}{\frac{\pi}{0}}$ & 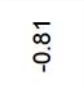 & \&: & in & $\stackrel{8}{\leftarrow}$ & 品 & ๙ু & 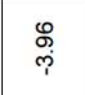 & & $\therefore \frac{y}{0}$ & $\begin{array}{l}\infty \\
\infty \\
i \\
i\end{array}$ & $\underset{\text { f }}{\stackrel{g}{2}}$ & 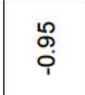 & ్ㅗㅇ & $\begin{array}{l}\infty \\
\infty \\
\stackrel{\infty}{\infty}\end{array}$ & $\underset{\infty}{\infty}$ \\
\hline & 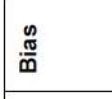 & $\stackrel{\stackrel{\sim}{i ̣ ~}}{i}$ & $\stackrel{\circ}{0}$ & J & 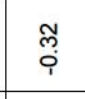 & $\stackrel{\sim}{\stackrel{\sim}{~}}$ & $\stackrel{\circ}{\circ}$ & ָ̊. & & 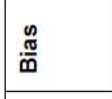 & $\begin{array}{l}\text { ț } \\
\text { in }\end{array}$ & $\stackrel{\mathscr{O}}{0}$ & $\begin{array}{l}\text { to } \\
\text { in }\end{array}$ & $\stackrel{\infty}{0}$ & $\stackrel{\infty}{\circ}$ & 웅 \\
\hline & 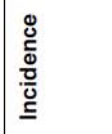 & $\begin{array}{l}\stackrel{?}{+} \\
\text { 㟧 }\end{array}$ & 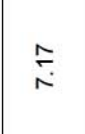 & 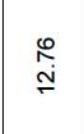 & $\begin{array}{l}\text { s. } \\
\stackrel{\text { N }}{ }\end{array}$ & $\begin{array}{l}\stackrel{8}{\infty} \\
\stackrel{\infty}{\sim}\end{array}$ & $\begin{array}{l}\text { O్ } \\
\text { d̦ }\end{array}$ & 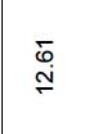 & & $\underset{\underline{\underline{\alpha}}}{\underline{\underline{\alpha}}}$ & $\underset{+\infty}{+\infty}$ & $\stackrel{\infty}{\stackrel{\infty}{\leftarrow}}$ & $\stackrel{\uparrow}{+}$ & $\stackrel{\text { d }}{-}$ & $\underset{\infty}{\hat{\infty}}$ & 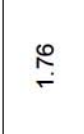 \\
\hline \multirow{5}{*}{ 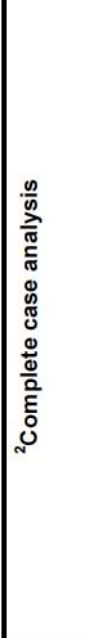 } & 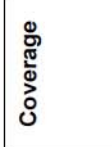 & ঃ̊ & : & $\stackrel{\circ}{\circ}$ & : & 웅 & 웅 & 웅 & \multirow{5}{*}{ 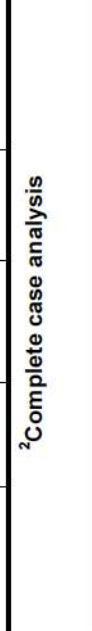 } & 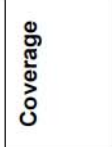 & $\stackrel{8}{\circ}$ & $\stackrel{8}{\circ}$ & $\stackrel{\circ}{\circ}$ & $\stackrel{\text { so }}{-}$ & $\stackrel{8}{\longrightarrow}$ & 웅 \\
\hline & 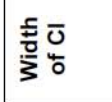 & $\stackrel{\circ}{\stackrel{ }{ }}$ & $\stackrel{9}{\sim}$ & $\underset{\infty}{\stackrel{\infty}{+}}$ & $\underset{\sigma}{\hat{\sigma}}$ & $\underset{\sim}{\mathbb{N}}$ & 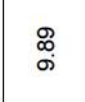 & 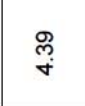 & & 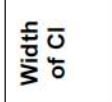 & $\stackrel{?}{\stackrel{?}{\leftarrow}}$ & $\begin{array}{l}\stackrel{0}{0} \\
0\end{array}$ & $\stackrel{\infty}{\stackrel{\infty}{\leftarrow}}$ & ọ & $\frac{\circ}{m}$ & $\stackrel{\infty}{\stackrel{\infty}{0}}$ \\
\hline & $\begin{array}{l}\frac{9}{0} \\
\frac{\pi}{0} \\
\frac{0}{0} \\
\circ\end{array}$ & 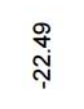 & $\begin{array}{l}\overline{0} \\
\text { ָ̦ }\end{array}$ & $\begin{array}{l}\infty \\
\infty \\
\infty \\
\infty \\
p\end{array}$ & $\stackrel{\circ}{\stackrel{\rho}{\sigma}}$ & 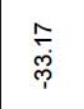 & ণ্ল్ల & 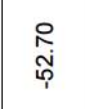 & & $\begin{array}{l}\frac{0}{0} \\
\frac{\pi}{0} \\
0 \\
0\end{array}$ & : & $\begin{array}{l}\hat{m} \\
\stackrel{p}{j}\end{array}$ & $\begin{array}{l}\stackrel{P}{9} \\
\stackrel{1}{+}\end{array}$ & $\underset{\hat{\varphi}}{\bar{\varphi}}$ & فิ & 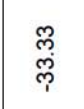 \\
\hline & 兽 & 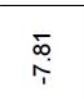 & $\stackrel{\infty}{\text { ஸ̆ }}$ & 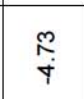 & $\stackrel{\stackrel{\infty}{\infty}}{\stackrel{\leftarrow}{\top}}$ & $\stackrel{5}{\dot{y}}$ & $\stackrel{\stackrel{\leftrightarrow}{\leftrightarrow}}{\stackrel{\leftrightarrow}{\top}}$ & $\underset{\wp}{\mathscr{\varphi}}$ & & 响 & J & ָָ & চo & $\frac{0}{i}$ & 芯 & চ্চি: \\
\hline & 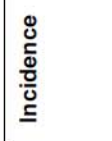 & $\begin{array}{l}\widetilde{\delta} \\
\stackrel{\sim}{0}\end{array}$ & i̊ & $\stackrel{\leftrightarrow}{\stackrel{\leftrightarrow}{\circ}}$ & $\underset{\substack{\stackrel{\infty}{\infty} \\
\stackrel{\infty}{\infty}}}{ }$ & $\begin{array}{l}\stackrel{q}{\infty} \\
\infty\end{array}$ & 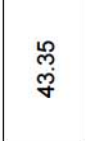 & 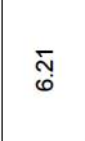 & & $\underset{\underline{\underline{\alpha}}}{\underline{\underline{\alpha}}}$ & ָָ & $\stackrel{g}{\stackrel{g}{+}}$ & $\bar{\sigma}$ & $\stackrel{\leftrightarrow}{\circ}$ & 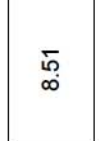 & $\underset{\mathfrak{N}}{ }$ \\
\hline 离畩 & 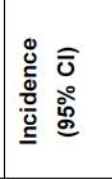 & 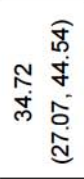 & 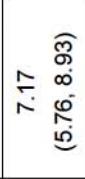 & 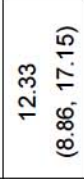 & 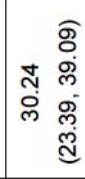 & 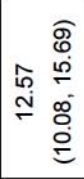 & 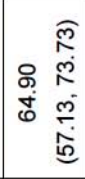 & 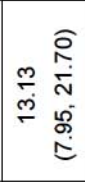 & 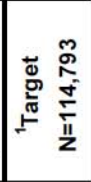 & 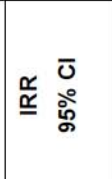 & 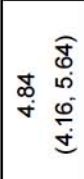 & 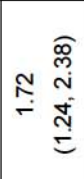 & 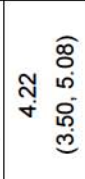 & 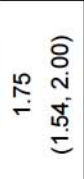 & 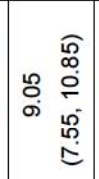 & 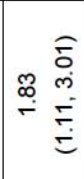 \\
\hline \multicolumn{2}{|c|}{ 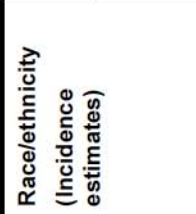 } & 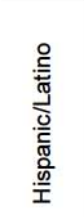 & 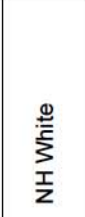 & 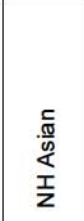 & $\begin{array}{l}\text { ․ } \\
\frac{\omega}{0} \\
\underline{M} \\
\frac{I}{z}\end{array}$ & 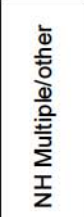 & $\begin{array}{l}\bar{a} \\
\frac{\bar{T}}{z} \\
\frac{1}{z}\end{array}$ & $\begin{array}{l}z \\
\frac{x}{4} \\
\frac{x}{z}\end{array}$ & \multicolumn{2}{|c|}{ 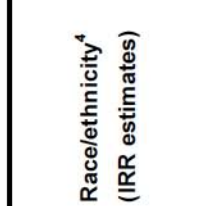 } & 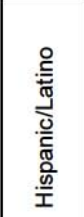 & $\begin{array}{l}\frac{c}{\frac{\pi}{0}} \\
\frac{0}{80} \\
\frac{1}{z}\end{array}$ & $\begin{array}{l}\frac{r}{0} \\
\frac{0}{\omega 0} \\
\frac{I}{z}\end{array}$ & 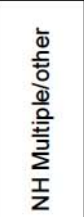 & $\begin{array}{l}\bar{a} \\
\frac{1}{z} \\
\frac{1}{z}\end{array}$ & $\begin{array}{l}z \\
\frac{x}{4} \\
\frac{1}{z}\end{array}$ \\
\hline
\end{tabular}




\begin{tabular}{|c|c|c|c|c|c|c|c|c|c|c|c|c|c|c|c|c|c|}
\hline \multirow{5}{*}{ 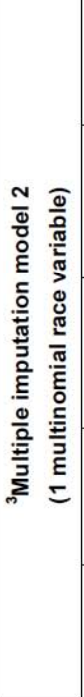 } & 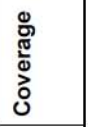 & $\stackrel{8}{\circ}$ & 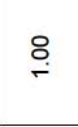 & $\stackrel{\leftrightarrow}{\circ}$ & 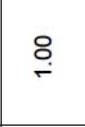 & ¿. & $\stackrel{8}{\circ}$ & $\stackrel{8}{\circ}$ & \multirow{5}{*}{ 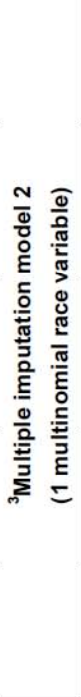 } & 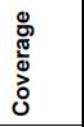 & $\stackrel{8}{\circ}$ & 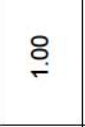 & $\stackrel{\text { }}{\circ}$ & $\stackrel{0}{\circ}$ & $\stackrel{8}{\circ}$ & $\stackrel{\leftrightarrow}{r}$ & $\begin{array}{l}\frac{\pi}{\pi} \\
\frac{\pi}{0} \\
0 \\
\frac{0}{6}\end{array}$ \\
\hline & 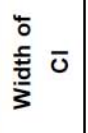 & 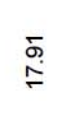 & $\underset{\text { ্ָ }}{\stackrel{\infty}{~}}$ & 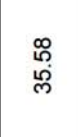 & $\stackrel{m}{\stackrel{m}{d}}$ & $\underset{\stackrel{\infty}{\leftrightarrow}}{\stackrel{\infty}{+}}$ & 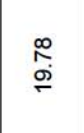 & $\underset{\underset{\sim}{\sim}}{\mathbb{N}}$ & & $\begin{array}{l}\text { t } \\
\frac{5}{5} \overline{0} \\
\frac{5}{3}\end{array}$ & 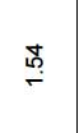 & 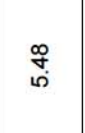 & $\underset{\text { స్ }}{\bar{j}}$ & ริ & $\stackrel{\triangleright}{\infty}$ & $\stackrel{\text { ֻ }}{\text { ֻ }}$ & $\begin{array}{l}\stackrel{0}{ \pm} \\
\underset{0}{0}\end{array}$ \\
\hline & 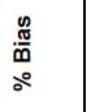 & $\stackrel{\text { op }}{\text { qu }}$ & 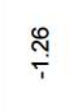 & \begin{tabular}{l}
$\stackrel{\infty}{N}$ \\
\multirow{f}{*}{}
\end{tabular} & $\stackrel{8}{\stackrel{+}{+}}$ & $\begin{array}{l}\stackrel{8}{0} \\
\stackrel{\leftrightarrow}{i}\end{array}$ & $\underset{\stackrel{\infty}{\leftrightarrow}}{\stackrel{\infty}{\leftrightarrow}}$ & 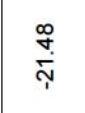 & & $\begin{array}{l}\frac{g}{ \pm 0} \\
\frac{\pi}{0} \\
\stackrel{\circ}{\circ}\end{array}$ & $\stackrel{\infty}{\infty}$ & 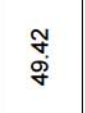 & 吊 & 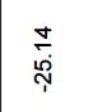 & 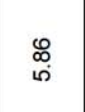 & $\begin{array}{l}\hat{\hat{\vartheta}} \\
\text { ஸิ }\end{array}$ & 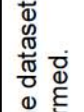 \\
\hline & 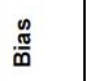 & $\frac{n}{i}$ & ò & 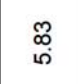 & $\frac{\bar{\sigma}}{\bar{T}}$ & $\underset{\text { ஸ̊ }}{\stackrel{\infty}{p}}$ & $\stackrel{\hat{N}}{\text { i }}$ & 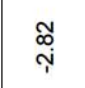 & & 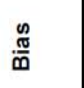 & $\stackrel{\text { ț }}{0}$ & $\stackrel{\substack{\infty \\
0}}{0}$ & $\stackrel{n}{i}$ & $\begin{array}{l}\text { J } \\
\stackrel{i}{1}\end{array}$ & مֶ: & $\stackrel{\infty}{\stackrel{\infty}{i}}$ & 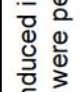 \\
\hline & 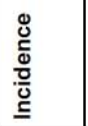 & 怘 & $\stackrel{\infty}{\sim}$ & $\stackrel{\infty}{\stackrel{\infty}{\infty}}$ & 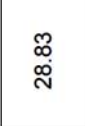 & $\underset{\text { ని }}{\text { న్ }}$ & $\begin{array}{l}\hat{\infty} \\
\stackrel{0}{0}\end{array}$ & $\stackrel{\bar{m}}{\stackrel{0}{\circ}}$ & & $\underset{\underline{\alpha}}{\underline{\underline{\alpha}}}$ & $\begin{array}{l}\infty \\
\infty \\
\stackrel{\sim}{\infty}\end{array}$ & $\stackrel{\hat{\omega}}{\text { th }}$ & to & $\stackrel{\bar{m}}{\sim}$ & 怘 & $\stackrel{g}{\stackrel{g}{r}}$ & 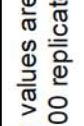 \\
\hline \multirow{5}{*}{ 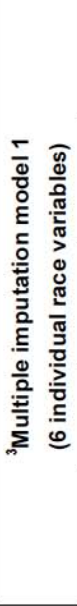 } & 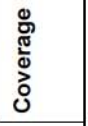 & $\stackrel{\text { }}{\circ}$ & 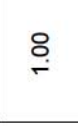 & $\stackrel{\leftrightarrow}{\circ}$ & $\stackrel{8}{\longrightarrow}$ & : & ஜू & $\stackrel{8}{\circ}$ & \multirow{5}{*}{ 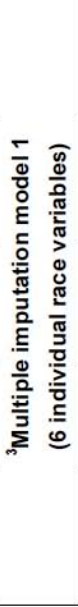 } & 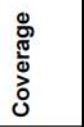 & 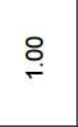 & $\stackrel{\circ}{\circ}$ & $\stackrel{8}{\circ}$ & $\stackrel{0}{\circ}$ & $\stackrel{\text { }}{\circ}$ & $\stackrel{\leftrightarrow}{\circ}$ & \\
\hline & 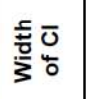 & 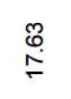 & స్లి & $\stackrel{\infty}{\stackrel{\infty}{\sim}}$ & $\underset{\text { I্ }}{\text { N }}$ & $\stackrel{F}{\stackrel{F}{F}}$ & $\begin{array}{l}\mathscr{Q} \\
\stackrel{\sigma}{\circ}\end{array}$ & 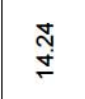 & & 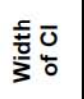 & $\stackrel{\text { fo }}{\leftarrow}$ & $\underset{+}{\stackrel{\leftrightarrow}{*}}$ & $\stackrel{\bar{\alpha}}{\sim}$ & $\stackrel{\overbrace{}}{\rightleftarrows}$ & $\underset{\sim}{\infty}$ & $\underset{\text { i }}{\stackrel{\text { S }}{ }}$ & $=$ \\
\hline & 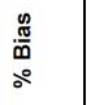 & $\underset{\leftarrow}{\leftarrow}$ & $\underset{\substack{i \\
p}}{N}$ & $\begin{array}{l}\text { ळ. } \\
\stackrel{\text { pे }}{2}\end{array}$ & $\begin{array}{l}\tilde{0} \\
\stackrel{0}{\complement}\end{array}$ & $\begin{array}{l}\bar{N} \\
\stackrel{\sim}{\Lambda}\end{array}$ & 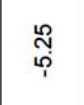 & ํㅗำ & & $\begin{array}{l}\frac{\mathscr{n}}{\%} \\
\frac{\mathscr{m}}{0} \\
\stackrel{\circ}{\circ}\end{array}$ & 心̂. & $\begin{array}{l}\stackrel{\leftrightarrow}{0} \\
\stackrel{\phi}{0}\end{array}$ & $\begin{array}{l}\hat{\omega} \\
\hat{\varphi}\end{array}$ & 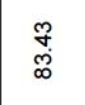 & 菅 & $\frac{m}{\frac{m}{T}}$ & 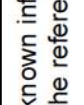 \\
\hline & $\frac{\mathscr{g}}{\frac{\pi}{m}}$ & \&̊ & సָ ִָ & $\underset{\infty}{\stackrel{\infty}{\infty}}$ & $\frac{\infty}{p}$ & $\underset{\infty}{\infty}$ & ষ্户 & 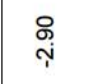 & & $\frac{\mathscr{g}}{\tilde{m}}$ & $\stackrel{\text { ָ̦ }}{\circ}$ & ֻั & 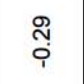 & $\stackrel{g}{\mathscr{T}}$ & $\frac{⿱}{i}$ & 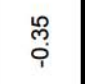 & \\
\hline & 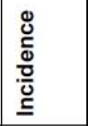 & $\begin{array}{l}\bar{i} \\
\text { ip }\end{array}$ & $\begin{array}{l}8 \\
0 \\
0\end{array}$ & $\stackrel{m}{\dot{\omega}}$ & $\underset{\sim}{\stackrel{\sim}{N}}$ & $\stackrel{\mathscr{L}}{\stackrel{N}{N}}$ & $\frac{\text { gे }}{\dot{6}}$ & 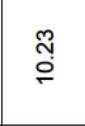 & & $\stackrel{\underline{\alpha}}{\underline{\underline{\alpha}}}$ & $\underset{\text { is }}{F}$ & $\stackrel{\text { N }}{\text { in }}$ & 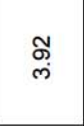 & 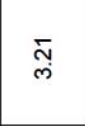 & $\underset{\infty}{\widetilde{\infty}}$ & 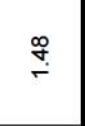 & \\
\hline \multirow{5}{*}{ 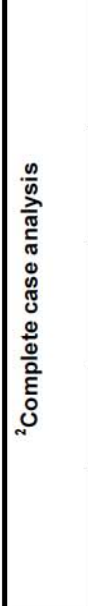 } & 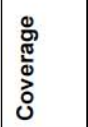 & $\stackrel{\text { so }}{-}$ & $\stackrel{8}{\circ}$ & $\stackrel{8}{\circ}$ & : & : & : & $\stackrel{\text { so }}{-}$ & \multirow{5}{*}{ 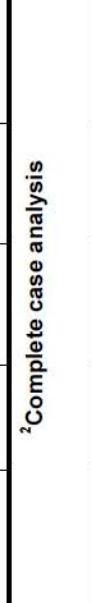 } & 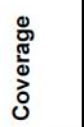 & $\stackrel{8}{0}$ & $\underset{\substack{\infty \\
0 \\
0}}{\infty}$ & $\stackrel{8}{\circ}$ & $\stackrel{\circ}{\circ}$ & : & 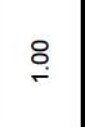 & \\
\hline & $\begin{array}{l}\frac{5}{5} \overline{0} \\
\frac{1}{3}\end{array}$ & $\begin{array}{l}\stackrel{R}{0} \\
\text { i }\end{array}$ & 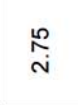 & is & $\underset{\stackrel{\infty}{\infty}}{\stackrel{\leftrightarrow}{\sim}}$ & 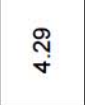 & $\begin{array}{l}\stackrel{\infty}{\infty} \\
\stackrel{\infty}{\infty} \\
\sim\end{array}$ & $\begin{array}{l}\text { g) } \\
\text { g }\end{array}$ & & 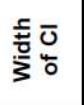 & $\underset{\mathfrak{t}}{\stackrel{5}{*}}$ & 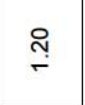 & 莽 & $\stackrel{\text { q }}{0}$ & $\stackrel{\stackrel{N}{ }}{\stackrel{m}{\sim}}$ & $\stackrel{\infty}{\sim}$ & \\
\hline & $\begin{array}{l}\frac{y}{\%} \\
\frac{0}{0} \\
\text { 。 }\end{array}$ & 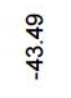 & $\begin{array}{l}\widetilde{0} \\
\infty \\
0 \\
1\end{array}$ & 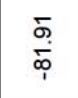 & 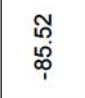 & 㝦 & ্ָ & 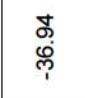 & & $\begin{array}{l}\frac{n}{0} \\
\frac{\pi}{0} \\
\frac{0}{0}\end{array}$ & $\stackrel{\hat{m}}{\stackrel{\infty}{\infty}}$ & 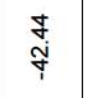 & 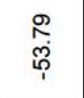 & $\begin{array}{l}\text { to } \\
\stackrel{0}{1}\end{array}$ & 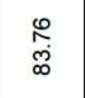 & $\begin{array}{l}\stackrel{ \pm}{\circ} \\
\stackrel{0}{\circ}\end{array}$ & \\
\hline & $\frac{\mathscr{m}}{\frac{m}{\omega}}$ & $\stackrel{\circ}{\stackrel{\circ}{\rho}}$ & $\underset{\sim}{\sim}$ & $\frac{\circ}{\circ}$ & 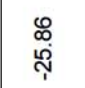 & 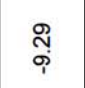 & 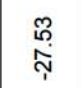 & $\begin{array}{l}\mathscr{\infty} \\
\dot{T}\end{array}$ & & 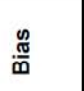 & $\underset{\text { je }}{\mathbb{\infty}}$ & 饣̂́ & 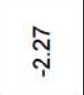 & ָָ & $\stackrel{\text { م }}{\stackrel{n}{N}}$ & $\stackrel{\infty}{\check{\infty}}$ & \\
\hline & 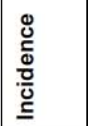 & 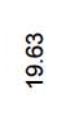 & $\stackrel{\sim}{\sim}$ & $\stackrel{\widetilde{N}}{\text { N }}$ & 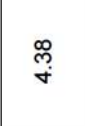 & 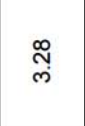 & 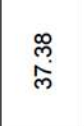 & $\underset{\infty}{\stackrel{\infty}{\infty}}$ & & $\stackrel{\underline{\alpha}}{\underline{\underline{\alpha}}}$ & $\underset{\infty}{\stackrel{N}{0}}$ & ஓ̊. & $\stackrel{\leftrightarrow}{\leftarrow}$ & $\stackrel{\varphi}{\stackrel{\varphi}{~}}$ & $\begin{array}{l}\ddot{8} \\
\stackrel{\leftrightarrow}{6}\end{array}$ & : & \\
\hline 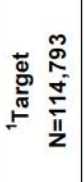 & 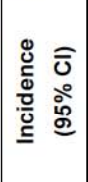 & 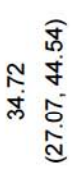 & 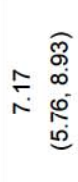 & 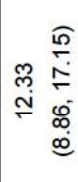 & 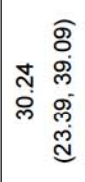 & 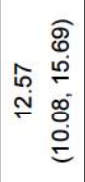 & 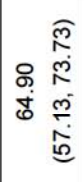 & 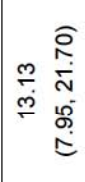 & 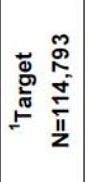 & 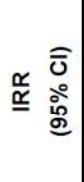 & 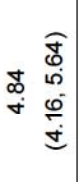 & 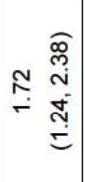 & 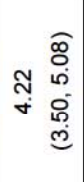 & 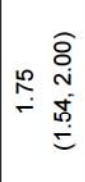 & 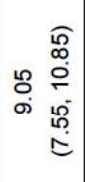 & 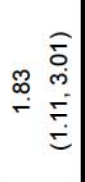 & $\begin{array}{l}0 \\
\frac{1}{0} \\
0 \\
\frac{\pi}{\pi} \\
\frac{\pi}{0} \\
0\end{array}$ \\
\hline \multicolumn{2}{|c|}{ 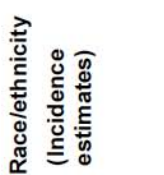 } & 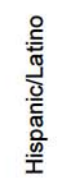 & 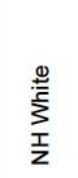 & $\begin{array}{l}\frac{c}{\frac{\pi}{0}} \\
\frac{0}{8} \\
\frac{I}{z}\end{array}$ & $\begin{array}{l}\frac{.}{0} \\
\frac{0}{0} \\
\frac{1}{z} \\
\frac{I}{z}\end{array}$ & 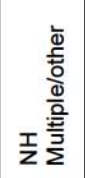 & $\begin{array}{l}\bar{a} \\
\frac{\bar{T}}{z} \\
\frac{I}{z}\end{array}$ & $\begin{array}{l}\frac{z}{x} \\
\frac{1}{\alpha} \\
\frac{1}{z}\end{array}$ & 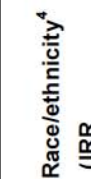 & & 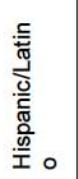 & $\begin{array}{l}\frac{c}{\frac{\pi}{\pi}} \\
\frac{\pi}{8} \\
\frac{I}{z}\end{array}$ & $\begin{array}{l}\frac{r}{0} \\
\frac{\omega}{0} \\
\frac{\pi}{z} \\
\frac{I}{z}\end{array}$ & 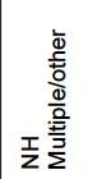 & $\begin{array}{l}\overline{\frac{1}{1}} \\
\frac{1}{z} \\
\frac{1}{z}\end{array}$ & $\begin{array}{l}\frac{z}{\alpha} \\
\frac{x}{2} \\
\frac{1}{z}\end{array}$ & के \\
\hline
\end{tabular}


Evaluations 1 and 2 assume data are missing at random. However, not all variables related to the missingness may be included in the propensity models due to limited individual-level information available in the case-level data. Moreover, it is possible that the missingness of race and ethnicity still depends on race and ethnicity after controlling all possible covariates, i.e., not missing at random (NMAR) missingness. To address this issue, a sensitivity analysis was conducted, repeating the Evaluation studies 1 and 2, with indicator variables on race and on ethnicity included in the propensity models to generate not missing at random missing data. Results found that Model 1 consistently reduced biases of complete case analysis and improved coverage for six race/ethnicity groups, except for the $\mathrm{NH}$ Multiple/other group. Imputation Model 2 yielded estimates with slightly larger biases compared to those of imputation Model 1 . More details of the sensitivity study can be found in Part 2 of the supplemental materials.

\section{DISCUSSION}

COVID-19 case surveillance provides valuable information on pandemic monitoring to inform public health efforts for epidemic control. Demographic information on race and ethnicity in case surveillance is essential to accurately assess racial and ethnic disparities in COVID-19 incidence and direct efforts to promote health equity. However, high levels of missing data on race and ethnicity and variation in missingness by state constrain the interpretability of estimates of disparities. Removing subjects with missing race/ethnicity information from the analysis may yield biased results and reduce statistical power for detecting health disparities.

To improve estimates and monitoring of COVID-19related measurements, different methods for grouping persons by race and ethnicity have been explored by Yoon et al., [5]. Their analysis shows that different grouping methods can lead to different conclusions about disparities when analyzing race and ethnicity data with missing values. Additional methods for analyzing incomplete race and ethnicity data are necessary to more accurately estimate race and ethnicity incidence and differences. Our study used MI to address the missing race/ethnicity in the case-level surveillance data. We merged county-level information on race/ethnicity distribution, population, and social and economic conditions to the COVID-19 case-level data to construct two MI models. A detailed evaluation of these models found incidence and IRR estimates from
Model 1 (imputing race using 6 individual variables) were closer to the true estimates for six race/ethnicity groups (all except the $\mathrm{NH}$ Multiple/other). Additional research is needed to identify methods of $\mathrm{Ml}$ to better estimate race/ethnicity for $\mathrm{NH}$ Multiple/other, which was over and under imputed in our two models. In our current analysis race Other was grouped with race Multiple as Multiple/other. An alternative, to be investigated, is to code race Other as the following. First, if race Other is the only race coded as "Yes" then treat it as missing. Second, if race Other and one additional race are coded as "Yes" then categorize the person's race as the additional race. Third, if race Other is classified as "Yes" and two additional races are classified as "Yes" then categorize the person's race as Multiple. In future research, the impact of this revised race algorithm should be explored. Our research highlights the importance of collecting complete race/ethnicity information for pandemic surveillance. When missing data exist, MI provides better incidence and IRR estimates to monitor health disparities among racial and ethnic groups. Our MI approach could be adapted to other surveillance data with similar statistical needs, such as COVID-19 vaccination data and other pandemic case-level data.

Our study has some limitations. First, MI model 1 tends to over impute $\mathrm{NH}$ Multiple/other group, which includes records with multiple race categories selected or Other race selected. Among the Hispanic/Latino group, the percentage of individuals with Other race selected was much higher compared to the NonHispanic/Latino group (32\% vs. $4.3 \%$, respectively). Although we included ethnicity as a covariate when imputing race, the higher percentage of Other race among the Hispanic/Latino group might lead to over imputation of Other race among the NonHispanic/Latino group. Imputing multiracial identities has previously been reported as a challenge [12] and deserves further investigation. Second, in the caselevel data, most of the person-level information is missing and can't be included in the imputation model. County-level information from census data was merged to perform imputation, which was demonstrated to be effective but may not be the best predictors of individual race and ethnicity. However, it has been shown to perform well in predicting the distributions of race and ethnicity at the aggregated group level [14]. Third, because the completeness of COVID-19 reporting and race/ethnicity missing rates vary by state, the assumption of MAR may not hold for some states. In Evaluations 1 and 2, we used propensity models 
from IA and PA to generate low and high levels of missing values, but the true missing data mechanism across states may be more complicated than IA and PA propensity models.

In summary, for national case reporting data with a large number of missing values for race/ethnicity, using MI can dramatically reduce the biases in incidence and IRR estimates compared to complete case analysis. Imputing source variables for race separately was more accurate than imputing race directly as a composite variable, which was also a recommended imputation strategy for composite categorical variables in a recent study [30]. Our research highlights the significant problems with incomplete race/ethnicity information for pandemic surveillance. Multiple Imputation resulted in more accurate incidence and incidence ratio estimates for different race/ethnicity groups. It can help fill critical gaps in cases surveillance completeness for race and ethnicity and should be considered to provide more accurate estimates for incidence and IRR in the COVID-19 pandemic.

\section{DISCLAIMER}

The findings and conclusions in this study are those of the authors and do not necessarily represent the official position of the U.S. Department of Health and Human Services, the Centers for Disease Control and Prevention, and the Health Resources and Services Administration

\section{SUPPLEMENTARY DATA}

The supplementary data can be downloaded from the journal website along with the article.

\section{REFERENCE}

[1] Wang Q, Berger NA, Xu R. Analyses of Risk, Racial Disparity, and Outcomes Among US Patients With Cancer and COVID-19 Infection. JAMA Oncol 2021; 7(2): 220-227. https://doi.org/10.1001/jamaoncol.2020.6178

[2] Yancy CW. COVID-19 and African Americans. JAMA 2020; 323(19): 1891-1892. https://doi.org/10.1001/jama.2020.6548

[3] Mahajan UV, Larkins-Pettigrew M. Racial demographics and COVID-19 confirmed cases and deaths: a correlational analysis of 2886 US counties. J Public Health 2020; 42(3): 445-447. https://doi.org/10.1093/pubmed/fdaa070

[4] Karaca-Mandic P, Georgiou A, Sen S. Assessment of COVID-19 hospitalizations by race/ethnicity in 12 states. JAMA Intern Med 2021; 181(1): 131-134.

https://doi.org/10.1001/jamainternmed.2020.3857

[5] Yoon P, Hall J, Fuld J, et al. Alternative Methods for Grouping Race and Ethnicity to Monitor COVID-19 Outcomes and Vaccination Coverage. MMWR Morb Mortal Wkly Rep 2021; 70: 1075-1080.

https://doi.org/10.15585/mmwr.mm7032a2

[6] Adjaye-Gbewonyo D, Bednarczyk RA, Davis RL, Omer SB. Using the Bayesian improved surname geocoding method (BISG) to create a working classification of race and ethnicity in a diverse managed care population: a validation study. Health Serv Res 2013; 49(1): 268-283. https://doi.org/10.1111/1475-6773.12089

[7] Hassett $P$. Taking on racial and ethnic disparities in health care: the experience at Aetna. Health Aff 2005; 24(2): 417420.

https://doi.org/10.1377/hlthaff.24.2.417

[8] Silva GC, Trivedi AN, Gutman R. Developing and evaluating methods to impute race/ethnicity in an incomplete dataset. Health Services and Outcomes Research Methodology 2019; 19: 175-195. https://doi.org/10.1007/s10742-019-00200-9

[9] Little RJA, Rubin DB. Statistical Analysis with Missing Data, New York: Wiley 2019 https://doi.org/10.1002/9781119482260

[10] Fiscella K, Fremont AM. Use of geocoding and surname analysis to estimate race and ethnicity. Health Serv Res 2006; 41(4 Pt 1): 1482-1500.

[11] Elliott MN, Fremont A, Morrison PA, Pantoja P, Lurie N. A new method for estimating race/ethnicity and associated disparities where administrative records lack self-reported race/ethnicity. Health Serv Res 2008; 43(5p1): 1722-1736. https://doi.org/10.1111/j.1475-6773.2008.00854.x

Elliott MN, Morrison PA, Fremont A, McCaffrey DF, Pantoja $P$, Lurie N. Using the Census Bureau's surname list to improve estimates of race/ethnicity and associated disparities. Health Serv Outcomes Res Methodol 2009; 9(2): 69. https://doi.org/10.1007/s10742-009-0047-1

[13] Grundmeier RW, Song L, Ramos MJ, et al. Imputing missing race/ethnicity in pediatric electronic health records: reducing bias with use of U.S. Census location and surname data. Health Serv Res 2015; 50(4): 946-960. https://doi.org/10.1111/1475-6773.12295

[14] Ma Y, Zhang W, Lyman S, Huang Y. The HCUP SID imputation project: improving statistical inferences for health disparities research by imputing missing race data. Health Serv Res 2018; 53(3): 1870-1889. https://doi.org/10.1111/1475-6773.12704

[15] Kim JS, Gao X, Rzhetsky A. RIDDLE: Race and ethnicity Imputation from Disease history with Deep Learning. PloS Comput Biol 2018; 14(4): e1006106. https://doi.org/10.1371/journal.pcbi.1006106

[16] Labgold K, Hamid S, Shah S, Gandhi NR, Chamberlain A, Khan F, Khan S, Smith S, Williams S, Lash TL, Collin LJ. Estimating the Unknown: Greater Racial and Ethnic Disparities in COVID-19 Burden After Accounting for Missing Race and Ethnicity Data. Epidemiology 2021; 32(2): 157161.

https://doi.org/10.1097/EDE.0000000000001314

[17] Schafer JL. Analysis of Incomplete Multivariate Data, London: Chapman and Hall 1997. https://doi.org/10.1201/9781439821862

[18] Raghunathan TE, Lebkowski JM, VanHoewyk J, Solenberger P. A Multivariate Technique for Multiply Imputing Missing Values Using a Sequence of Regression Models. Survey Methodology 2001; 27: 85-95.

[19] Van Buuren S. Multiple Imputation of Discrete and Continuous Data by Fully Conditional Specification. Statistical Methods in Medical Research 2007; 16: 219-242. https://doi.org/10.1177/0962280206074463

[20] Van Buuren S. Flexible Imputation of Missing Data, Boca Raton, FL: Chapman \& Hall/CRC 2012. 
[21] He Y. Missing Data Analysis Using Multiple Imputation: Getting to the Heart of the Matter. Circulation: Cardiovascular Quality and Outcomes 2010; 3: 98-105. https://doi.org/10.1161/CIRCOUTCOMES.109.875658

[22] Van Buuren S, Karin G. Mice: Multivariate Imputation by Chained Equations in R. Journal of Statistical Software, 2011; 45(3).

https://doi.org/10.18637/jss.v045.i03

[23] Liu Y, De A. Multiple Imputation by Fully Conditional Specification for Dealing with Missing Data in a Large Epidemiologic Study. International Journal of Statistics in Medical Research 2015; 4(3): 287-295. https://doi.org/10.6000/1929-6029.2015.04.03.7

[24] SAS Institute Inc. SAS/STAT® 14.1 User's Guide. Cary, NC: SAS Institute Inc. 2015

[25] Rubin DB. Multiple Imputation in Sample Surveys - A Phenomenological Bayesian Approach to Nonresponse. In Proceedings of the Section on Survey Research Methods., American Statistical Association 1978; pp. 20-34.
[26] Rubin DB. Multiple Imputation for Nonresponse in Surveys, New York: John Wiley 1987. https://doi.org/10.1002/9780470316696

[27] Rubin DB. Multiple Imputation After 18+ Years. Journal of the American Statistical Association 1996; 91: 473-489. https://doi.org/10.1080/01621459.1996.10476908

[28] Rubin DB, Schenker N. Multiple Imputation for Interval Estimation from Simple Random Samples with Ignorable Nonresponse. Journal of the American Statistical Association 1986; 81: 366-374.

https://doi.org/10.1080/01621459.1986.10478280

[29] Barnard J, Rubin DB. Small-Sample Degrees of Freedom with Multiple Imputation. Biometrika 1999; 86: 948-955. https://doi.org/10.1093/biomet/86.4.948

[30] Pan Y, He Y, Song R, Wang G, An Q. A passive and inclusive strategy to impute missing values of a composite categorical variable with an application to determine HIV transmission categories. Ann Epidemiol 2020; 51: 41-47.e2. https://doi.org/10.1016/..annepidem.2020.07.012

https://doi.org/10.6000/1929-6029.2022.11.01

() 2022 Zhang et al.; Licensee Lifescience Global.

This is an open access article licensed under the terms of the Creative Commons Attribution License (http://creativecommons.org/licenses/by/4.0/) which permits unrestricted use, distribution and reproduction in any medium, provided the work is properly cited. 